\title{
Bezrobocie w transporcie drogowym towarów w kontekście zmian przepisów unijnych o delegowaniu pracowników
}

\author{
Radostaw Gajewski* \\ Klaudia Pilichowska**
}

Streszczenie: W opracowaniu poruszono tematykę rozwoju transportu drogowego w kontekście zapotrzebowania na pracowników, które na terenie Unii Europejskiej rozkłada się nierównomiernie. Celem przeprowadzonych badań było określenie wpływu zmiany przepisów unijnych dotyczących delegowania pracowników na bezrobocie w wybranych krajach UE. W artykule przedstawiono charakterystykę bezrobocia w największych gospodarkach Unii Europejskiej. Wprowadzenie nowej dyrektywy unijnej ma służyć wyrównaniu płac w transporcie drogowym we wszystkich krajach unijnych, co ma spowodować utratę przewagi konkurencyjnej firm z Europy Środkowo-Wschodniej. Metody badawcze wykorzystane w artykule to analiza literatury i danych Głównego Urzędu Statystycznego oraz Eurostatu.

Słowa kluczowe: bezrobocie, stopa bezrobocia, transport drogowy, delegowanie pracowników.

\section{Wstęp}

W Unii Europejskiej na rynku transportowym panuje ogromna konkurencja. Przedsiębiorstwa rywalizują ze sobą ceną, jakością usług oraz flotą samochodową. Rządy krajów, które tracą udziały w tym rynku, wprowadzają ograniczenia dla obcokrajowców chcących działać na ich terytorium. Do barier, jakie tworzą, można zaliczyć przede wszystkim wysokość płac minimalnych, również dla obcokrajowców, ryczałty za noclegi, a także zmiany w dyrektywie o delegowaniu pracowników na terytorium innego kraju.

* Politechnika Częstochowska, Wydział Zarządzania.

** Politechnika Częstochowska, Wydział Zarządzania. 
Obecna sytuacja międzynarodowego transportu drogowego jest niestabilna z powodu zmieniających się przepisów unijnych. Celem artykułu jest analiza wpływu zmiany przepisów o delegowaniu pracowników na poziom bezrobocia w wybranych krajach Unii Europejskiej w kontekście transportu drogowego towarów.

\section{Typy bezrobocia oraz skutki jego występowania}

Definiując pojęcie bezrobocia, zauważono złożoność tego pojęcia. E. Kwiatkowski określa bezrobocie jako zjawisko braku pracy zarobkowej wśród osób w wieku produkcyjnym ${ }^{1}$. Według Głównego Urzędu Statystycznego (GUS) do osób w wieku produkcyjnym zalicza się mężczyzn mających od 18 do 64 lat oraz kobiety między 18. a 59. rokiem życia ${ }^{2}$. Podając definicję osoby bezrobotnej, warto podkreślić, iż nie jest to jedynie osoba, która nie ma pracy, lecz taka, która jest gotowa do jej podjęcia. Bezrobocie to zatem liczba osób w wieku produkcyjnym, które są zdolne do podjęcia pracy przy obowiązujących w danym momencie stawkach płac, lecz nieposiadających zatrudnienia ${ }^{3}$. Do mierzenia poziomu bezrobocia wykorzystujemy miernik, jakim jest stopa bezrobocia, czyli odsetek siły roboczej, który pozostaje bez pracy, ale jest zarejestrowany jako poszukujący pracy ${ }^{4}$. Miernik ten wyrażany jest w jednostce procentowej.

W zależności od przyczyn występowania bezrobocia wyróżnia się kilka jego rodzajów. Najczęściej spotykamy się z podziałem na następujące rodzaje bezrobocia ${ }^{5}$ :

- strukturalne - występuje w przypadku niedostosowania kwalifikacji pracownika do zapotrzebowania pracodawcy, podczas gdy struktura popytu i produkcji wciąż się zmienia;

- frykcyjne (płynne, naturalne) - występuje w każdym szybko zmieniającym się społeczeństwie i dotyczy osób, które poprzez różne ułomności mają utrudnione podjęcie pracy zawodowej lub przejściowo poszukują pracy z innych powodów;

- klasyczne - pojawia się wówczas, gdy płaca jest utrzymywana powyżej poziomu, na którym krzywe popytu i podaży na pracę przecinają się;

- wynikające z niedostatku popytu (zwane keynesowskim) - występuje, gdy faktyczna produkcja jest mniejsza od produkcji potencjalnej.

1 E. Kwiatkowski, Bezrobocie. Podstawy teoretyczne, Wydawnictwo Naukowe PWN, Warszawa 2002, s. 14.

2 Pojęcia stosowane w statystyce publicznej, Główny Urząd Statystyczny, https://stat.gov.pl/ metainformacje/slownik-pojec/pojecia-stosowane-w-statystyce-publicznej/861,pojecie. html [dostęp 22.02.2018].

3 N. Mankiw, M. Taylor, Makroekonomia, Wydawnictwo Naukowe PWN, Warszawa 2009, s. 95-96.

4 D. Begg, G. Vernasca, S. Fischer, R. Dornbusch, Makroekonomia, PWE, Warszawa 2004, s. 304.

5 Ibidem, s. 310-311. 
Ponadto wyróżniamy ${ }^{6}$

- bezrobocie technologiczne - wynikające ze zmiany technologii i unowocześniania zakładu pracy, w którym praca ludzka jest zastępowana pracą maszyn;

- bezrobocie koniunkturalne - występujące w zależności od koniunktury; gdy koniunktura jest wysoka, to popyt wzrasta, a bezrobocie obniża się do poziomu naturalnego.

Duże bezrobocie wywołuje negatywne następstwa w wymiarze politycznym, ekonomicznym i społecznym. Do skutków politycznych można zaliczyć przejawy rosnącej frustracji osób bezrobotnych oraz ich rodzin, co przeradza się w społeczny anarchizm. Dochodzi do różnego rodzaju masowych strajków czy wystąpień przeciwko danemu porządkowi społecznemu i gospodarczemu. Za ekonomiczne skutki bezrobocia należy uznać duże koszty z nim związane, zarówno z punktu widzenia całego społeczeństwa, jak i jednostki ${ }^{7}$. Natomiast względem społeczeństwa koszty związane $\mathrm{z}$ osobą bezrobotną definiowane są jako alternatywne, przez co rozumie się wartość dóbr oraz usług, które osoba ta mogłaby wytworzyć, gdyby pracowała ${ }^{8}$.

\section{Stopa bezrobocia w wybranych krajach UE}

Na podstawie analizy literatury przedmiotu, danych z Głównego Urzędu Statystycznego oraz Europejskiego Urzędu Statystycznego (Eurostatu) można stwierdzić, że rynek pracy w krajach Unii Europejskiej jest bardzo zróżnicowany i dynamicznie się zmienia. W zależności od poziomu rozwoju danego kraju rynek może oferować określoną liczbę miejsc pracy, która nie jest wystarczająca względem wielkości populacji. Z problemem wysokiego bezrobocia boryka się wiele krajów Unii Europejskiej, a największe bezrobocie występuje wśród ludzi młodych. Na przełomie 2016 i 2017 r. wśród osób do 25. roku życia bezrobocie wynosiło około 4 mln młodych osób ${ }^{9}$, zaś około 20 mln wszystkich bezrobotnych w Europie, w tym 15,6 mln w strefie euro ${ }^{10}$. Analizując dane dotyczące bezrobocia w UE

6 M. Barańska, Wybrane teorie bezrobocia. Wybrane zagadnienia rynku pracy, http://docplayer. pl/39379939-Wybrane-teorie-bezrobocia.html [dostęp 7.12.2017], s. 2-3.

7 Z. Dach, B. Szopa (red.), Podstawy makroekonomii, PTE, Kraków 2004, s. 162-163.

8 N. Mankiw, M. Taylor, op. cit., s. 117.

9 Bezrobocie wśród młodzieży - czy polityka UE wpłynęła na zmianę sytuacji? Ocena gwarancji dla młodzieży i inicjatywy na rzecz zatrudnienia ludzi młodych, Europejski Trybunał Obrachunkowy, Sprawozdanie specjalne nr 5/2017, https://www.eca.europa.eu/Lists/.../SR17_5/ SR_YOUTH_GUARANTEE_PL.pdf [dostęp 22.02.2018], s. 6 .

10 Polska wśród krajów z najniższym bezrobociem w UE. Najnowsze dane Eurostatu (2017), Polsat News, http://www.polsatnews.pl/wiadomosc/2017-03-02/polska-wsrod-krajow-znajnizszym-bezrobociem-w-ue-najnowsze-dane-eurostatu [dostęp 28.11.2017]. 
wśród młodych ludzi, można zauważyć, że wartość w tej grupie wiekowej maleje ${ }^{11}$. Powodem bezrobocia wśród młodych osób jest m.in. brak doświadczenia oraz wiedzy zawodowej w tej grupie. Wiele przedsiębiorstw poszukujących pracowników chce zatrudnić osoby z doświadczeniem zawodowym, co najczęściej stanowi barierę dla studiujących lub osób zaraz po studiach. Warto jednak podkreślić, że kraje UE zdecydowały się na zmiany w systemach edukacyjnych, pozwalając na zdobywanie doświadczenia przez studentów w trakcie nauki. Była to korzystna decyzja, a jednym z pierwszych państw, które ją wdrożyło, były Niemcy ${ }^{12}$. Przyczyniło się to do bardzo niskiej stopy bezrobocia w tym kraju. Analizując sytuację ekonomiczną danego kraju, warto więc zestawić ją ze stopą bezrobocia tego kraju.

W kontekście zmiany przepisów o delegowaniu pracowników przeanalizowano dane dotyczące poziomu bezrobocia w pięciu największych państwach UE, które są istotne dla sektora transportu drogowego. Kraje te zostały wybrane do badania ze względu na wysokość płacy minimalnej i ilość przewożonych towarów w międzynarodowym transporcie drogowym w porównaniu z Polską. Zarówno dla obywateli Polski, jak i innych krajów z niskimi płacami minimalnymi państwa Europy Zachodniej są atrakcyjnym rynkiem pracy, ponieważ koszty utrzymania pracownika są tam znacznie wyższe. W krajach Europy Środkowo-Wschodniej rentowność prowadzenia firmy jest wyższa niż w Europie Zachodniej.

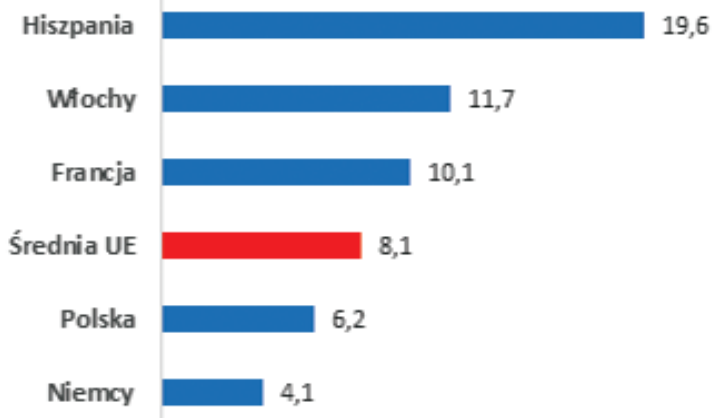

Wykres 1. Stopa bezrobocia w wybranych krajach UE w 2016 r.

Źródło: opracowanie własne na podstawie danych Eurostatu: Unemployment rate - annual data, Eurostat, http://ec.europa.eu/eurostat/tgm/table.

do?tab=table\&init=1\&plugin=1\&pcode=tipsun20\&language=en [dostęp 7.12.2017].

Na wykresie 1. możemy zaobserwować, jak stopa bezrobocia w Hiszpanii, Włoszech, Francji, Niemczech oraz w Polsce wypada na tle średniej w Unii Europej-

11 Bezrobocie młodych po kryzysie: Polska na tle UE (2014), https://rynekpracy.pl/artykuly/bezrobocie-mlodych-po-kryzysie-polska-na-tle-ue [dostęp 25.04.2018].

12 Sytuacja na rynkach pracy w krajach UE jest zróżnicowana, widmo bezrobocia wśród młodych, HR News, http://www.hrnews.pl/Artykul,3700,Sytuacja-na-rynkach-pracy-w-krajach-UE-jest -zroznicowana-widmo-bezrobocia-wsrod-mlodych.aspx [dostęp 20.11.2017]. 
skiej (średnia stopa bezrobocia w krajach UE ze stycznia 2017 r.). Najlepszy wynik osiągnęły Niemcy, gdzie stopa bezrobocia wynosi 4,1\%. Odzwierciedla to również bardzo dobra sytuacja gospodarcza tego kraju na tle innych państw UE. Porównując dane dotyczące stopy bezrobocia w 2016 r. względem roku poprzedniego, odnotowujemy następujące spadki:

- Hiszpania - 2,5 p.p. (najwyższe bezrobocie w UE);

- Włochy - 0,2 p.p.;

- Francja-0,3 p.p.;

- Polska - 1,3 p.p.;

- Niemcy - 0,5 p.p.

Eurostat opublikował również dane dotyczące roku 2017, które prezentuje tabela 1.

Tabela 1. Stopa bezrobocia - dane kwartalne, wyrównane sezonowo w 2017 r. w wybranych krajach UE

\begin{tabular}{|l|c|c|c|c|}
\hline \multirow{2}{*}{ Kraje } & \multicolumn{4}{|c|}{$\mathbf{4 0 1 7}$} \\
\cline { 2 - 5 } & kwartat I & kwartat II & kwartat III & kwartat IV \\
\hline Niemcy & 3,9 & 3,8 & 3,7 & 3,6 \\
\hline Hiszpania & 18,2 & 17,3 & 16,8 & 16,6 \\
\hline Francja & 9,6 & 9,5 & 9,5 & 9,0 \\
\hline Włochy & 11,6 & 11,2 & 11,2 & 11,0 \\
\hline Polska & 5,2 & 5,1 & 4,8 & 4,6 \\
\hline
\end{tabular}

Źródło: opracowanie własne na podstawie danych Eurostatu: Unemployment rate, Eurostat, http://ec.europa.eu/eurostat/search?p_auth=KIHVy3dE\&p_p_id=estatsearchportlet_WAR_ estatsearchportlet\&p_p_lifecycle=1\&p_p_state=maximized\&p_p_mode=view\&_estatsearchportlet_ WAR_estatsearchportlet_text=Unemployment+rate\&_estatsearchportlet_WAR_estatsearchportlet_ sort=lastUpdateDate\&_estatsearchportlet_WAR_estatsearchportlet_action=search\&_ estatsearchportlet_WAR_estatsearchportlet_pageNumber=1 (dostęp: 10.12.2017) oraz Unemployment rate - quarterly data, seasonally adjusted, Eurostat, http://ec.europa.eu/eurostat/tgm/table.do?tab=table \&init=1\&plugin=1\&pcode=tipsun30\&language=en [dostęp 24.04.2018].

Zmniejszająca się stopa bezrobocia jest korzystna i została odnotowana we wszystkich wybranych do analizy krajach UE, tj. w Hiszpanii, Niemczech, Francji, Włoszech oraz w Polsce. Warto zauważyć, że bezrobocie jest w inny sposób badane przez Eurostat weryfikujący osoby pomiędzy 15. a 74. rokiem życia, które podejmują zarobkową działalność, uczą się bądź pobierają emeryturę ${ }^{13}$.

Analizując powyższe dane, można spostrzec, że Polska na tle krajów UE wypada bardzo dobrze. Zgodnie z danymi z GUS wielu obywateli Polski jest zatrudnionych w sektorze przedsiębiorstw. W okresie od stycznia do października 2017 r. zatrudniono 5999,4 tys. osób, co stanowi wzrost o 4,4 p.p. w stosunku do roku 
2016. Ponadto, zatrudnienie pracowników wzrastało najbardziej m.in. w sektorze transportu oraz gospodarki magazynowej o $7 \%{ }^{14}$.

Transport jest sektorem, który znacznie wspiera gospodarkę naszego kraju oraz ma duży udział w tworzeniu PKB. Dane z 2016 r. wyrażają jego wartość w granicach $8-10 \%{ }^{15}$. Polska na tle całej Unii Europejskiej jest od 2007 r. liderem w międzynarodowych przewozach towarów ${ }^{16}$. Śledząc dane zebrane przez Eurostat widzimy, że wartość ta nieustanie wzrasta, a ponadto przez ostatnie 9 lat Polska nie miała konkurencji, która mogłaby jednoznacznie zagrozić jej pozycji i doprowadzić do spadku ilości przewożonych towarów. Poniżej zaprezentowano wykres 2. przedstawiający pozycję poszczególnych krajów w międzynarodowym transporcie drogowym.

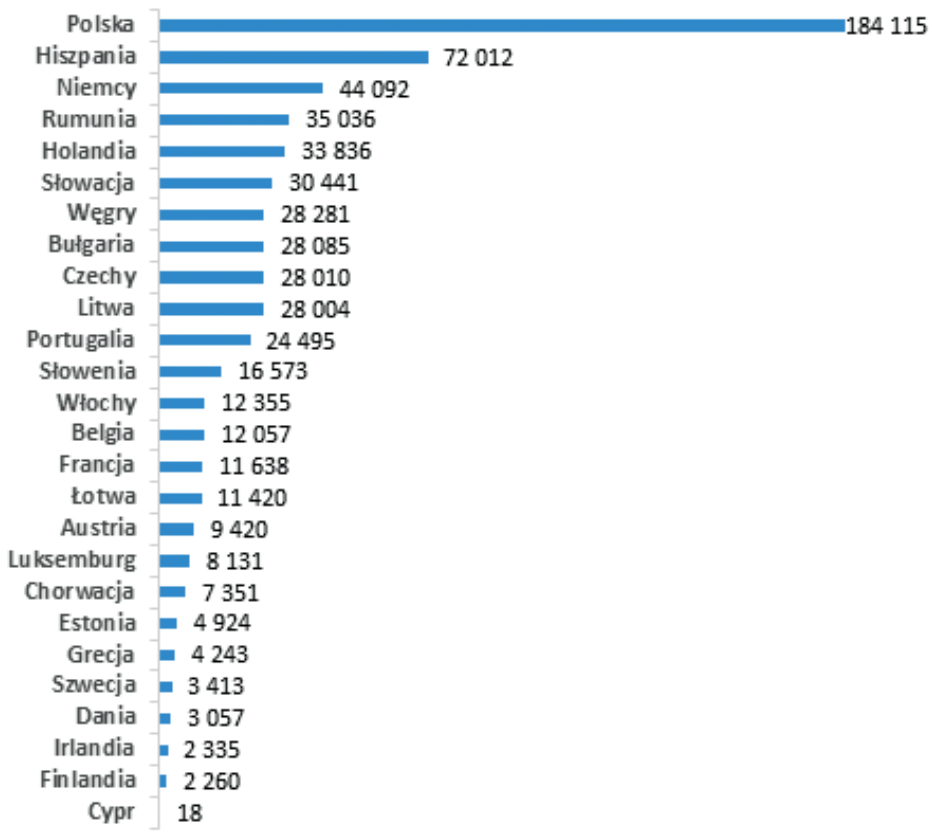

Wykres 2. Międzynarodowy przewóz towarów transportem drogowym w poszczególnych krajach UE w 2016 r. [mln tonokilometrów]

Źródto: opracowanie własne na podstawie danych Eurostatu: Summary of annual road freight transport by type of operation and type of transport (2017), Eurostat, http://appsso.eurostat. ec.europa.eu/nui/show.do?dataset=road_go_ta_tott\&lang=en [dostęp 27.11.2017].

14 Informacja o sytuacji społeczno-gospodarczej kraju w październiku 2017 r.), Główny Urząd Statystyczny (listopad 2017), https://stat.gov.pl/obszary-tematyczne/inne-opracowania/informacje-o-sytuacji-spoleczno-gospodarczej/informacja-o-sytuacji-spoleczno-gospodarczejkraju-w-pazdzierniku-2017-r-,1,66.html?contrast=black-white [dostęp 20.01.2018], s. 5-7.

15 Polska lideruje w UE w transporcie drogowym, Polska Gazeta Transportowa 2016, http://www. pgt.pl/polska-lideruje-w-ue-w-transporcie-drogowym [dostęp 28.11.2017].

16 Summary of annual road freight transport by type of operation and type of transport, Eurostat 2017, http://appsso.eurostat.ec.europa.eu/nui/show.do?dataset=road_go_ta_tott\&lang=en [dostęp 27.11.2017]. 
Z wykresu 2., na którym zostały uwzględnione wszystkie kraje UE, jednoznacznie wynika, że polskie firmy transportowe w 2016 r. przewiozły najwięcej towarów. Przewoźnicy ze wszystkich krajów europejskich osiągnęli łączny wynik 647597 mln tonokilometrów. Pierwsze miejsce (z wynikiem 28\% przewiezionych towarów) zajęła Polska, kolejno uplasowały się Hiszpania (11\%) i Niemcy $(7 \%)^{17}$. Wysokie miejsce Polski wynika z konkurencyjnych cen oraz położenia geograficznego naszego kraju ${ }^{18}$. Fakt, że Polska jest liderem w opisanym rankingu niepokoi konkurencję, która nieustanie próbuje ograniczyć jej dominację poprzez wprowadzanie wielu restrykcji. Chodzi m.in. o wprowadzane płace minimalne, ryczałty za noclegi ${ }^{19}$ czy nowelizacje przepisów o delegowaniu pracowników.

\section{Znaczenie zmian w dyrektywie o delegowaniu pracowników w kontekście transportu drogowego}

Rozmowy o zmianach w unijnej dyrektywie o delegowaniu pracowników rozpoczęto w sierpniu 2017 r. Pomysłodawcą reformy jest Francja, w imieniu której występuje prezydent Emmanuel Macron. Bezrobocie w tym kraju jest wyższe niż średnia w UE, na co wpływ ma również zmniejszenie się udziału Francji w rynku transportowym. Zmiany w dyrektywie unijnej miałyby nastąpić poprzez wprowadzenie ścisłych uregulowań dotyczących delegowania pracowników celem uniknięcia wielu nadużyć w tym zakresie, które zdaniem Francji przyczyniają się do niewłaściwej konkurencji. Władze francuskie w pierwszym kroku wprowadziły zmiany obejmujące swoje terytorium. Doprowadziły do wzrostu maksymalnej kary za łamanie prawa w powyższym zakresie z 10 tys. do 500 tys. euro oraz do zwiększenia działań kontrolujących. Następnie Francja zdecydowała się na rozszerzenie omawianych działań poza własny kraj. Prezydent Francji, aby zwiększyć swój wpływ na zmiany w przepisach unijnych, zdecydował się na wizytę w wybranych państwach UE w celu uzyskania ich poparcia. W pierwszej kolejności odwiedził te, które są powiązane i zależne gospodarczo od Francji, a więc Cze-

17 Ibidem.

18 W Polsce brakuje 100 tys. kierowców ciężarówek, a chętnych nie ma (2017), https://moto.wp.pl/ w-polsce-brakuje-100-tys-kierowcow-ciezarowek-a-chetnych-nie-ma-6100998483550849a [dostęp 28.02.2018].

19 R. Kozłowski, R. Gajewski, K. Pilichowska, Identyfikacja i charakterystyka problemów polskich przedsiębiorstw transportu drogowego zwiq̨zanych z ochrona rynków przez rządy wybranych krajów, [w:] K. Kapuścińska, S. Lachiewicz i M. Matejun (red.), Współczesne organizacje wobec wyzwań zarządzania ryzykiem - aspekty poznawcze, Wydawnictwo Politechniki Łódzkiej, Łódź 2015. 
chy, Słowację, Bułgarię i Rumunię̨ ${ }^{20}$. Krajami szczególnie zainteresowanymi rozmową o zmianach w dyrektywie były Polska i Węgry, jednak zostały one pominięte podczas wizyty Macrona. Jak się okazało, wizyta prezydenta Francji przyniosła oczekiwane przez niego efekty i wspomniane cztery kraje poparły zmiany, których skutki są niekorzystne dla nich samych ${ }^{21}$. Dla państw Europy Środkowo-Wschodniej, w tym Polski, bardzo ważne jest, aby zmiany w dyrektywie nie dotyczyły branży transportowej (transportu wewnątrzwspólnotowego, kabotażu, tranzytu), co nie zostało uwzględnione w końcowym stanowisku. Innego zdania jest Francja, która uważa, że rynek ten również powinien podlegać tym przepisom. Ważnym punktem negocjacji było ustalenie czteroletniego okresu przejściowego, w którym dyrektywa o delegowaniu pracowników nie będzie stosowana, a przedsiębiorstwa będą mogły przygotować się do jej obowiązywania oraz zapoznać się z nowymi przepisami ${ }^{22}$. W dniu 24 października 2017 r. podczas posiedzenia Parlamentu Europejskiego zostało zatwierdzone stanowisko komisji do spraw zatrudnienia dotyczące zmian w dyrektywie o delegowaniu - wbrew oczekiwaniom Polski, Łotwy, Litwy i Węgier. Najważniejsze zmiany w dyrektywie dotyczą następujących zakresów ${ }^{23}$ :

- zarobków delegowanych pracowników (czyli osób wysyłanych na określony czas do innego państwa członkowskiego UE, aby tam wykonać określone usługi świadczone przez wysyłające przedsiębiorstwo);

- czasu trwania delegowania,

- zbiorowych układów pracy,

- pracowników tymczasowych.

Korzystnym zapisem w dyrektywie jest podtrzymanie zasady, według której koszty związane $\mathrm{z}$ zakwaterowaniem, wyżywieniem i transportem wypłacane są zgodnie z przepisami prawnymi wysyłającego państwa. Należy jednak podkreślić, że sukces w negocjacjach nad zmianami w dyrektywie odniósł przede wszystkim prezydent Francji oraz kraje, które są skupione w tzw. sojuszu paryskim. Chodzi tutaj m.in. o Niemcy, Belgię, Włochy czy Luksemburg ${ }^{24}$.

20 Macron chce zmian w dyrektywie o pracownikach delegowanych. Rusza w podróż do Europy Środkowej, ale pomija Polskę, Wyborcza.pl 2017, http://wyborcza.pl/7,75399,22264946,macron-chce-zmian-w-dyrektywie-o-pracownikach-delegowanych.html [dostęp 3.12.2017].

21 Dla jednych to porażka, a inni sa zadowoleni. Nie wszystko stracone ws. delegowania pracowników (2017), https://trans.info/jeszcze-nie-wszystko-stracone-ws-delegowania-pracownikow69440?utm_campaign=naglowek_w_TransInfo\&utm_source=ramka_w_PZ\&utm_mediu$\mathrm{m}=$ news [dostęp 27.11.2017].

22 Kiepskie wieści ws. delegowania pracowników. Polska przegrała bitwę o transport (2017), https:// trans.info/delegowanie-pracownikow-unijni-ministrowie-dalecy-od-porozumienia-69343 [dostęp 4.12.2017].

23 Europosłowie dali zielone światło. Dyrektywa o delegowaniu będzie przedmiotem kolejnych rozmów (2017), https://trans.info/europoslowie-dali-zielone-swiatlo-dyrektywa-o-delegowaniubedzie-przedmiotem-kolejnych-rozmow-69502?utm_campaign=naglowek_w_TransInfo\&utm_source=ramka_w_PZ\&utm_medium=news [dostęp 4.12.2017].

24 Dla jednych to porażka, a inni sa zadowoleni. Nie wszystko stracone ws. delegowania pracowników (2017), https://trans.info/jeszcze-nie-wszystko-stracone-ws-delegowania-pracownikow- 
Nawiązując do zmian wprowadzonych w unijnej dyrektywie o delegowaniu pracowników, warto zwrócić uwagę na to, jakie kraje delegują ich najwięcej. $\mathrm{Na}$ pierwszym miejscu, z rekordową liczbą, jest Polska, która wysyła 463174 pracowników. Drugie miejsce zajmują Niemcy z 240862 pracownikami, zaś na trzecim miejscu jest Francja z 139040 swoimi obywatelami. Uzasadnione jest poparcie dyrektywy przez Hiszpanię delegującą znaczną liczbę pracowników, czyli 125 711, ponieważ zrównanie płacy minimalnej może spowodować zwiększenie się tej liczby, a w konsekwencji zmniejszenie bezrobocia w tym kraju. Poniżej zamieszczono rysunek 1. uwzględniający zestawienie wysyłanych pracowników w wybranych krajach Unii Europejskiej.

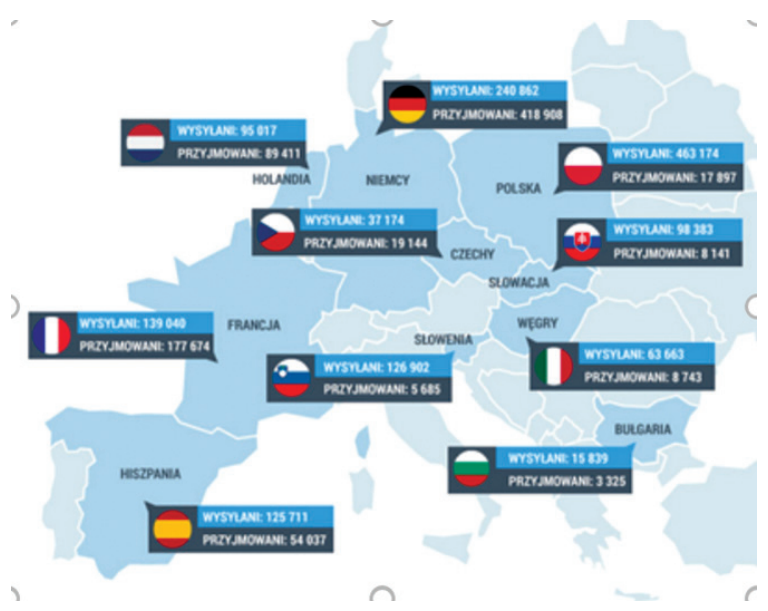

Rysunek 1. Delegowani pracownicy w wybranych krajach Unii Europejskiej

Źródto: Delegowanie pracowników. Dlaczego Czechy i Rumunia nie zagłosowały jak Polska? (2017), https://trans.info/delegowanie-pracownikow-dlaczego-czechy-i-rumunia-niezaglosowaly-jak-polska-69686?utm_campaign=naglowek_w_TransInfo\&utm_source=ramka_W_PZ\&utm_medium=news [dostęp 27.11.2017].

Analizując dane przedstawione na rysunku 1., można stwierdzić, że najwięcej do stracenia mają właśnie polskie przedsiębiorstwa, ponieważ Polska wysyła za granicę aż 2,9\% osób czynnych zawodowo. Francja czy Niemcy delegują duże liczby pracowników, jednak względem pracującej populacji tych państw jest to odpowiednio $0,6 \%$ oraz $0,5 \%$. W kontekście powyższego rysunku można wywnioskować, dlaczego te, a nie inne kraje poparły zmiany w dyrektywie o delegowaniu pracowników. Prezes Stowarzyszenia Inicjatywa Mobilności Pracy, Stefan Schwarz powiedział, że przegłosowanie stanowiska Rady Unii Europejskiej było „polityczną demonstracją siły bogatej Europy", z prezydentem Macronem na czele, względem biedniejszych krajów. Jest to pewnego rodzaju wyznaczenie zasad, na pod- 
stawie których państwa mogą konkurować z najbogatszymi na unijnym rynku, co ma dokładne odzwierciedlenie w sektorze transportowym ${ }^{25}$. W przypadku Francji doszła do głosu chęć ograniczenia konkurencji na rynku i próba przejęcia go. Wynika ona z dość wysokiej stopy bezrobocia we Francji, sytuującej się powyżej średniej w krajach UE. Pozornie wypracowany kompromis oznacza zatem wyłączenie z zachodniego rynku wielu polskich (i nie tylko) przewoźników ${ }^{26}$.

Obecna sytuacja $\mathrm{w}$ transporcie drogowym jest bardzo niestabilna. Kolejne lata mogą okazać się przełomowe dla rynku europejskich przewozów drogowych, a rynek transportowy może bardzo się zmienić. Wskutek wprowadzania wielu nowelizacji i ograniczeń istnieje wysokie prawdopodobieństwo, że zabraknie miejsca na jednolitym rynku dla wielu tysięcy polskich firm. Obawa o utratę pracy wynika $z$ analizy sytuacji na rynku oraz opisanych wyżej działań legislacyjno-politycznych. Jednym ze zjawisk rynkowych jest również niedobór kierowców w Polsce w liczbie ok. 100 tys. ${ }^{27}$ Skutki zapowiadanych zmian mogą być też niekorzystne dla krajów UE ze względu na wzrost kosztów oraz wydłużenie czasów dostaw towarów ${ }^{28}$.

\section{Wnioski}

Transport drogowy jest rynkiem szeroko konkurencyjnym, w którym decydujące znaczenie mają kraje bogate. Dzięki swoim wpływom są one w stanie wynegocjować takie warunki, które będą dla nich korzystne. W przypadku transportu drogowego chodzi o wykluczanie z międzynarodowego rynku krajów, które w tym sektorze dobrze sobie radzą, mając przy tym niską stopę bezrobocia - takim państwem jest chociażby Polska. Zmiany w przepisach o delegowaniu pracowników mają wpływ na strukturę bezrobocia w krajach Unii Europejskiej na korzyść krajów z Europy Zachodniej, kosztem tych z Europy Środkowej i Wschodniej. Prognozując skutki

25 Delegowanie pracowników. Dlaczego Czechy i Rumunia nie zagłosowały jak Polska? (2017), https://trans.info/delegowanie-pracownikow-dlaczego-czechy-i-rumunia-nie-zaglosowalyjak-polska-69686?utm_campaign=naglowek_w_TransInfo\&utm_source=ramka_w_ oPZ\&utm_medium=news [dostęp 27.11.2017].

26 Fałszywy kompromis? Co tak naprawdę ustalita Rada UE w kwestii delegowania w transporcie drogowym?, Centrum prasowe 2017, http://centrumprasowe.pap.pl/cp/pl/news/ info/108359,25,falszywy-kompromis-co-tak-naprawde-ustalil [dostęp 28.11.2017].

27 W Polsce brakuje 100 tys. kierowców ciężarówek, a chętnych nie ma (2017), https://moto.wp.pl/ w-polsce-brakuje-100-tys-kierowcow-ciezarowek-a-chetnych-nie-ma-6100998483550849a [dostęp 28.02.2018].

28 M. Wroński, Absurdalne owoce unijnej legislacji transportowej, „Transport Manager” 2017, nr 29, s. 34-35. 
zmiany przepisów o delegowaniu pracowników, można spodziewać się przesunięcia wzrostu bezrobocia w branży transportowej z Europy Zachodniej do krajów Środkowo-Wschodniej części Europy. W przypadku Polski jego poziom może wzrosnąć, jeśli małe przedsiębiorstwa nie podołają wyzwaniom stawianym przez omawianą dyrektywę. Jeśli chodzi o Francję, to uzasadnione jest, że prezydent Macron zabiegał o wprowadzenie zmian w życie, ponieważ są one korzystne dla francuskich obywateli. Dla tego państwa dyrektywa o delegowaniu pracowników może być „lekarstwem” na wysokie bezrobocie rzędu 10,1\%. Ograniczając konkurencyjność na rynku, kraj ten dąży do przejęcia udziałów w międzynarodowych przewozach towarów w transporcie drogowym i zmniejszenia bezrobocia na swoim terytorium, przyczyniając się tym samym do zwiększenia bezrobocia w innych krajach.

Ponadto, w wyniku przeprowadzonych analiz można stwierdzić, że:

- zmiana w dyrektywie jest reformą, która skutkuje powstaniem nowego rodzaju bezrobocia - można je nazwać bezrobociem akcesyjnym, ponieważ wynika ono z akcesji unijnych przepisów dotyczących delegowania pracowników;

- dyrektywa o delegowaniu pracowników to głównie przejaw rywalizacji w zakresie swobody świadczenia usług transportowych oraz konkurencyjności na rynku;

- celem wprowadzenia dyrektywy jest wyrównanie płac w transporcie drogowym, co spowoduje utratę przewagi konkurencyjnej firm z środkowo-wschodniej części Europy;

- w Polsce odnotowuje się bezrobocie poniżej średniej UE, w wyniku czego w wielu sektorach brakuje pracowników, natomiast dobra sytuacja w transporcie dodatkowo potęguje to zjawisko.

\section{Bibliografia}

Barańska M., Wybrane teorie bezrobocia. Wybrane zagadnienia rynku pracy, http:// docplayer.pl/39379939-Wybrane-teorie-bezrobocia.html [dostęp 7.12.2017].

Begg D., Vernasca G., Fischer S., Dornbusch R. (2014), Makroekonomia, Polskie Wydawnictwo Ekonomiczne, Warszawa.

Bezrobocie młodych po kryzysie: Polska na tle UE (2014), https://rynekpracy.pl/artykuly/bezrobocie-mlodych-po-kryzysie-polska-na-tle-ue [dostęp 25.04.2018]. Bezrobocie wśród młodzieży - czy polityka UE wpłynęła na zmianę sytuacji? Ocena gwarancji dla młodzieży i inicjatywy na rzecz zatrudnienia ludzi młodych, Europejski Trybunał Obrachunkowy, Sprawozdanie specjalne nr 5/2017, https:// 
www.eca.europa.eu/Lists/.../SR17_5/SR_YOUTH_GUARANTEE_PL.pdf [dostęp 22.02.2018].

Dach Z., Szopa B. (red.) (2004), Podstawy makroekonomii, PTE, Kraków.

Delegowanie pracowników. Dlaczego Czechy i Rumunia nie zagłosowały jak Polska?

(2017), https://trans.info/delegowanie-pracownikow-dlaczego-czechy-i-rumunianie-zaglosowaly-jak-polska-69686?utm_campaign=naglowek_w_TransInfo\&utm_source=ramka_w_PZ\&utm_medium=news [dostęp 27.11.2017].

Dla jednych to porażka, a inni sa zadowoleni. Nie wszystko stracone ws. delegowania pracowników (2017), https://trans.info/jeszcze-nie-wszystko-stracone-wsdelegowania-pracownikow-69440?utm_campaign=naglowek_w_TransInfo\&utm_source=ramka_w_PZ\&utm_medium=news [dostęp 27.11.2017].

Europosłowie dali zielone światło. Dyrektywa o delegowaniu będzie przedmiotem kolejnych rozmów (2017), https://trans.info/europoslowie-dali-zielone-swiatlo-dyrektywa-o-delegowaniu-bedzie-przedmiotem-kolejnych-rozmow69502?utm_campaign=naglowek_w_TransInfo\&utm_source=ramka_w_ PZ\&utm_medium=news [dostęp 4.12.2017].

Fałszywy kompromis? Co tak naprawdę ustaliła Rada UE w kwestii delegowania $w$ transporcie drogowym? (2017), Centrum prasowe, http://centrumprasowe. pap.pl/cp/pl/news/info/108359,25, falszywy-kompromis-co-tak-naprawdeustalil [dostęp 28.11.2017].

Informacja o sytuacji społeczno-gospodarczej kraju w październiku 2017 r. (listopad 2017), Główny Urząd Statystyczny, https://stat.gov.pl/obszary-tematyczne/ inne-opracowania/informacje-o-sytuacji-spoleczno-gospodarczej/informacja-o-sytuacji-spoleczno-gospodarczej-kraju-w-pazdzierniku-2017-r-,1,66. html?contrast=black-white [dostęp 20.01.2018].

Kiepskie wieści ws. delegowania pracowników. Polska przegrała bitwę o transport (2017), https://trans.info/delegowanie-pracownikow-unijni-ministrowie-dalecy-odporozumienia-69343 [dostęp 4.12.2017].

Kozłowski R., Gajewski R., Pilichowska K. (2015), Identyfikacja i charakterystyka problemów polskich przedsiębiorstw transportu drogowego zwiazanych z ochroną rynków przez rządy wybranych krajów, [w:] K. Kapuścińska, S. Lachiewicz, M. Matejun (red.), Współczesne organizacje wobec wyzwań zarządzania ryzykiem - aspekty poznawcze, Wydawnictwo Politechniki Łódzkiej, Łódź.

Kwiatkowski E. (2002), Bezrobocie. Podstawy teoretyczne, Wydawnictwo Naukowe PWN, Warszawa.

Macron chce zmian $w$ dyrektywie o pracownikach delegowanych. Rusza $w$ podróż do Europy Środkowej, ale pomija Polskę (2017), Wyborcza.pl, http://wyborcza.pl/7,75399,22264946,macron-chce-zmian-w-dyrektywie-o-pracownikach-delegowanych.html [dostęp 3.12.2017].

Mankiw N., Taylor M. (2009), Makroekonomia, Wydawnictwo Naukowe PWN, Warszawa. 
Pojęcia stosowane w statystyce publicznej, Główny Urząd Statystyczny, https:// stat.gov.pl/metainformacje/slownik-pojec/pojecia-stosowane-w-statystycepublicznej/861,pojecie.html [dostęp 22.02.2018].

Polska lideruje w UE w transporcie drogowym (2016), Polska Gazeta Transportowa, http:// www.pgt.pl/polska-lideruje-w-ue-w-transporcie-drogowym [dostęp 28.11.2017].

Polska wśród krajów z najniższym bezrobociem w UE. Najnowsze dane Eurostatu (2017), Polsat News, http://www.polsatnews.pl/wiadomosc/2017-03-02/ polska-wsrod-krajow-z-najnizszym-bezrobociem-w-ue-najnowsze-daneeurostatu [dostęp 28.11.2017].

Summary of annual road freight transport by type of operation and type of transport (2017), Eurostat, http://appsso.eurostat.ec.europa.eu/nui/show.do?dataset=road_go_ta_tott\&lang=en [dostęp 27.11.2017].

Sytuacja na rynkach pracy w krajach UE jest zróżnicowana, widmo bezrobocia wśród młodych, HR News, http://www.hrnews.pl/Artykul,3700,Sytuacja-na-rynkach-pracy-w-krajach-UE-jest-zroznicowana-widmo-bezrobocia-wsro d-mlodych.aspx [dostęp 20.11.2017].

Unemployment rate - annual data, Eurostat, http://ec.europa.eu/eurostat/tgm/table.do?tab=table\&init=1 \&plugin=1 \&pcode=tipsun20\&language $=$ en $\quad[$ dostęp 7.12.2017].

Unemployment rate - quarterly data, seasonally adjusted, Eurostat, http://ec.europa.eu/eurostat/tgm/table.do?tab=table\&init=1\&plugin=1\&pcode=tipsun $30 \&$ language $=$ en [dostęp 24.04.2018].

Unemployment rate, Eurostat, http://ec.europa.eu/eurostat/search?p_auth=KIHVy3dE\&p_p_id=estatsearchportlet_WAR_estatsearchportlet\&p_p_lifecycle=1\&p_p_state $=$ maximized \&p_p_mode $=$ view\&_estatsearchportlet_WAR_ estatsearchportlet_text=Unemployment+rate\&_estatsearchportlet_WAR_estatsearchportlet_sort=lastUpdateDate\&_estatsearchportlet_WAR_estatsearchportlet_action=search\&_estatsearchportlet_WAR_estatsearchportlet_ pageNumber=1 [dostęp 10.12.2017].

W Polsce brakuje 100 tys. kierowców ciężarówek, a chętnych nie ma (2017), https:// moto.wp.pl/w-polsce-brakuje-100-tys-kierowcow-ciezarowek-a-chetnychnie-ma-6100998483550849a [dostęp 28.02.2018].

Wroński M. (2017), Absurdalne owoce unijnej legislacji transportowej, „Transport Manager", nr 29.

\section{Unemployment in transport goods by road in the context of changes of UE regulations about delegation of workers}

Abstract: The paper discusses the development of road transport in the context of the demand for workers, which is unevenly distributed across the European Union. The aim of the study was to determine the impact of the amendment of EU legislation on posting of 
workers on unemployment in selected EU countries. The article presents the characteristics of unemployment in the largest economies of the European Union. The introduction of the new EU directive is aimed at equalizing road transport salaries in all EU countries, which is expected to result in the loss of competitive advantage of companies from Central and Eastern Europe. The research methods used in the article are the analysis of literature and data of the Central Statistical Office and Eurostat.

Keywords: unemployment, unemployment rate, road transport, posing of workers. 